\title{
Charge Selectivity of the Glomerular Filtration Barrier in Healthy and Nephrotic Humans
}

\author{
Antonio Guasch, William M. Deen, and Bryan D. Myers \\ Nephrology Division, Stanford University Medical Center, Stanford, California 94305
}

\begin{abstract}
We used dextran sulfate (DS) to evaluate barrier charge selectivity in 11 nonproteinuric subjects and in 11 patients with the nephrotic syndrome due to either membranous nephropathy or minimal change nephropathy. The ${ }^{3} \mathbf{H}-\mathrm{DS}$ preparation spanned

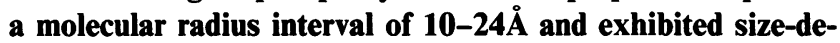
pendent protein binding in vitro. Urine and ultrafiltrates of plasma were separated by size into narrow fractions using gel permeation chromatography. The sieving coefficient $(\theta)$ for ultrafilterable DS of $15 \AA$ radius averaged $0.68 \pm 0.03$ in nonproteinuric vs. $0.95 \pm 0.05$ in nephrotic subjects $(P<0.001)$. Uncharged dextrans of broad size distribution were used to evaluate barrier size-selectivity in separate groups of nonproteinuric subjects $(n=19)$ and nephrotic patients with either minimal change $(n=20)$ or membranous nephropathy $(n=27)$. The value of $\theta$ for an uncharged dextran of similarly small radius ( 18 $)$ was significantly larger than that observed for DS in nonproteinuric subjects, but was similar in nephrotic individuals. Further, impaired barrier size-selectivity, as assessed by

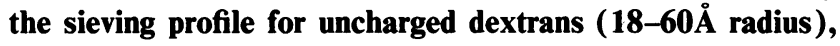
failed to account fully for the observed level of albuminuria in almost half of the patients with either minimal change $(9 / 20)$ or membranous nephropathy $(12 / 27)$. Together these findings suggest that the human glomerular capillary wall normally provides an electrostatic barrier to filtration of negatively charged macromolecules such as albumin, and that impairment of this electrostatic barrier contributes to the magnitude of albuminuria in the nephrotic syndrome. (J. Clin. Invest. 1993. 92:2274-2282.) Key words: dextran sulfate sieving • fractional protein clearances $\bullet$ pore theory $\bullet$ protein binding $\bullet$ uncharged dextran sieving
\end{abstract}

\section{Introduction}

The Bowman's space fluid-to-plasma concentration ratio, or sieving coefficient $(\theta)$, of a macromolecule of known radius and charge density provides the most direct measure of the intrinsic barrier properties of the glomerular capillary wall (GCW). ${ }^{1}$ Provided that a filtered macromolecule is neither

Address reprint requests to Dr. Bryan D. Myers, Nephrology Division (S-201), Stanford University Medical Center, 300 Pasteur Drive, Stanford, CA 94305.

Received for publication 22 January 1993 and in revised form 7 June 1993.

1. Abbreviations used in this paper: GCW, glomerular capillary wall; GPC, gel permeation chromatography; ${ }^{3} \mathrm{H}-\mathrm{DS}$, tritiated dextran sulfate; PAH, para-aminohippurate.

J. Clin. Invest.

(C) The American Society for Clinical Investigation, Inc.

$0021-9738 / 93 / 11 / 2274 / 09 \$ 2.00$

Volume 92, November 1993, 2274/2282 reabsorbed nor secreted by the tubule, dividing its urinary clearance by that of freely filtered inulin corrects for water reabsorption along the nephron, and the quotient yields the value for $\theta$ (1). Because endogenous proteins undergo a variable rate of tubular reabsorption, they cannot be used to elucidate the barrier properties of the $\operatorname{GCW}(2,3)$. Instead, investigators have employed a variety of nonreabsorbable exogenous polymers for this purpose (4-6).

The substance most widely used to characterize the size selective properties of the human GCW is dextran 40 , an uncharged and polydisperse polymer of glucopyranose. It is composed of component molecules, which vary between 18 and $70 \AA ̊$ in radius. A consistent finding in nephrotic subjects with a variety of underlying glomerular diseases has been a selective elevation above normal values of $\theta$ for large, nearly impermeant dextrans of $>50 \AA$ in radius (7-14). With the use of pore theory this finding has been interpreted to indicate that the GCW is perforated by two parallel populations of pores, which vary widely in radius. Pores of relatively low radius ( $\sim 50 \AA)$ dominate the GCW and are inferred to restrict the passage of plasma proteins the size of albumin and larger. Pores of large radius are relatively few in number but are inferred not to discriminate among macromolecules of up to $60 \AA$ in radius, behaving in effect as a shunt pathway (15). Immunoglobulin $\mathrm{G}$ ( $\mathrm{IgG})$, a large protein of $55 \AA \AA$ in radius, has been estimated to permeate the shunt-like pores at a rate sufficient to explain fully the observed level of immunoglobulinuria in nephrotic subjects $(7,9,11)$. However, the corresponding rate for transmembrane shunting of albumin does not always account completely for the observed magnitude of the urinary excretion rate of this relatively small (radius $=36 \AA$ ) but strongly anionic protein $(9,11)$.

This finding raises the possibility that the smaller, restrictive pores of the GCW might normally hinder passage of albumin on the basis of its charge as well as its size $(5,16)$. According to this hypothesis, an abundance of negatively charged sites within the GCW could retard albumin electrostatically, preventing it from gaining access to the smaller, restrictive pores that dominate the GCW. Depletion of these negatively charged sites consequent upon glomerular injury could impair the electrostatic retardation of albumin, permitting it to pass through the predominant smaller pores as well as those which are enlarged and shuntlike, thereby accounting for the phenomenon of nephrotic-range proteinuria. Support for this hypothesis comes from the demonstration that the GCW of the healthy rat restricts the passage of anionic dextran sulfate (DS) more than that of an uncharged dextran of equivalent size. In contrast, the GCW of the proteinuric rat cannot discriminate among dextran molecules on the basis of their charge $(5,17)$. To elucidate whether this is true also of the human GCW we have estimated the $\theta$ for both anionic and uncharged dextrans of discrete radius in subjects with either normal or nephrotic levels of proteinuria. 


\section{Methods}

Patient population. We studied barrier charge selectivity toward DS in 14 patients who were attending our clinic because of the development of a nephrotic syndrome due to biopsy-proven minimal change or membranous nephropathy. We selected patients with the latter two disorders for study because the morphology of all glomeruli in their biopsy cores was uniformly altered, suggesting a generalized glomerular injury. They were aged between 20 and $73 \mathrm{yr}$ and eight were male. Eleven of the patients had not received treatment and exhibited nephrotic range proteinuria $(>3.5 \mathrm{~g} / 24 \mathrm{~h})$ at the time of study. The remaining three patients, all with minimal change nephropathy, had entered a complete remission of proteinuria $(<0.2 \mathrm{~g} / 24 \mathrm{~h})$ after a 3-mo course of cyclosporine therapy. Eight healthy volunteers whose age varied between 21 and $31 \mathrm{yr}$, and five of whom were males, served as controls. All denied a history of renal disease, hypertension and diabetes, and each tested negative for proteinuria by dipstick.

In a parallel study of barrier size selectivity toward uncharged dextran 40 we studied an additional 47 nephrotic patients ( 20 with minimal change nephropathy and 27 with membranous nephropathy) and 19 healthy controls. The age range was similar (15-71 yr for nephrotics and 18-54 yr for controls) and the male gender was predominant in each group. The uncharged dextran sieving data for approximately one half of the nephrotic subjects of the parallel study group have been reported previously $(9,11)$.

Protocol. Patients and volunteers were admitted to the General Clinical Research Center at Stanford University Medical Center. Differential solute clearances were performed during water diuresis after each subject had given informed consent to the procedure. Either uncharged dextran $40(130 \mathrm{mg} / \mathrm{kg})$ or $100 \mu \mathrm{Ci}$ of tritiated DS $\left({ }^{3} \mathrm{H}-\mathrm{DS}\right)$ was infused as a bolus along with inulin $(50 \mathrm{mg} / \mathrm{kg}$ ) and para-aminohippurate (PAH, $12 \mathrm{mg} / \mathrm{kg}$ ). Dextran 40, inulin, and PAH (but not ${ }^{3} \mathrm{H}$-DS) were then infused continuously to maintain the plasma concentration of each marker constant. After a 60 -min equilibration period, four carefully timed 30 -min urine collections were made along with bracketing samples of plasma. The average urinary clearance of inulin was equated with the GFR. The corresponding clearance of PAH divided by an estimate of its renal arteriovenous extraction ratio was used to derive the rate of renal plasma flow (18). An additional determinant of GFR, the oncotic pressure of plasma, was determined by membrane osmometry.

The $\theta$ for uncharged dextrans in the parallel study was determined after separation of dextran molecules in urine and deproteinized plasma of the first collection period into narrow $2 \AA$ fractions over the 18-60Å molecular radius interval. This was accomplished by gel permeation chromatography (GPC), using Ultragel ACA 44 (LKB, Inc., Pleasant Hill, CA). The $\theta$ for each discrete fraction was derived by dividing its urine-to-plasma concentration ratio by that of inulin. An autoanalyzer technique which has been described elsewhere was used to assay inulin, PAH, and dextran concentrations (7-10). An enzymelinked immunosorbent assay was used to determine the simultaneous clearances of endogenous IgG and albumin (7-10). The dextran sulfate used in both clearance and various in vitro studies was tritiated, and its specific activity in all biological and artificial fluids was determined by scintillation counting. Samples were mixed 1:10 parts with Cytoscint-ES scintillation fluid (ICN Biomedicals, Irvine, CA) and counted for 10 min on a model LS-9000 scintillation counter (Beckman Instruments, Inc., Fullerton, CA).

Physicochemical properties of dextran sulfate. We selected DS as a probe of the filtration barrier because it has been shown to be neither reabsorbed nor secreted by the tubule (5). Comparing its $\theta$ to that of uncharged dextran of similar size thus provides a convenient method for isolating the charge-selective properties of the GCW. The preparation used in the present study was a gift from its manufacturer, Ueno Fine Chemicals, Inc., Osaka, Japan. Its use as an investigational drug had been approved by the U. S. Food and Drug Administration for the treatment of patients with HIV infection. This approval was extended to include its use in the present study as a probe of the glomerular charge-selective barrier in humans. Based on the pharmacokinetic properties of the preparation, we calculated that a dose in the toxic range would have to be infused to achieve steady-state plasma concentrations within the range assayable by anthrone or refractive index (19). We accordingly obtained permission from our Institutional Review Board to label the preparation with tritium and administer a tracer dose of $100 \mu \mathrm{Ci}$.

The tritiation was performed by the Research Products Division of New England Nuclear Corp. (Boston, MA). DS (1,000 mg) was dissolved in $3 \mathrm{ml}$ of water. Using $150 \mathrm{mg}$ of $5 \% \mathrm{Rh} / \mathrm{Al}_{2} \mathrm{O}_{3}$ as a catalyst, 30 $\mathrm{Ci}$ of tritium gas was added to the solution and the reaction stirred for $48 \mathrm{~h}$ at room temperature. We then passed $1 \mathrm{mCi}$ of the final preparation over desalting columns (Econo-Pac 10 DG, Bio-Rad Laboratories, Hercules, CA) to remove free tritium, which accounted for $70 \%$ of the radioactivity.

We determined the molecular radius distribution of the final ${ }^{3} \mathrm{H}-\mathrm{DS}$ preparation using GPC over an 82-cm-long column with an internal diameter of $5 \mathrm{~cm}$. The column bed was Sephadex G75 (Pharmacia Fine Chemicals, Uppsala, Sweden) which we calibrated with four narrow fractions of dextran of known radius provided by Pharmacia. A $0.3 \%$ solution of sodium chloride was used as the eluent. The ${ }^{3} \mathrm{H}$-DS exhibited a Gaussian distribution of radii ranging from 10 to $24 \AA$ with a peak radius at $16 \AA$ (Fig. 1). The same GPC technique revealed our inulin preparation (Isotex Ltd., Austin, TX) to have an essentially identical distribution of radii (Fig. 1). The sulfate content of the dextran sulfate preparation was estimated to be $13.5 \%$ by Galbraith Laboratories, Inc. (Knoxville, TN), indicating it to be strongly anionic.

Adsorbent columns containing dextran sulfate have recently been shown by Knisel et al. (20) to remove a variety of serum proteins during the extracorporeal circulation of human plasma. To estimate the extent of protein binding by DS we performed in vitro experiments using both equilibrium dialysis (Spectrum Medical Industries, Los Angeles, CA) and a stirred cell ultrafiltration apparatus (Amicon Corp., Beverly, MA). A membrane with a $50 \mathrm{kD}$ molecular weight cutoff was employed in both systems. All experiments were performed at room temperature using a stir bar to achieve continuous rotation of the sample in order to avoid concentration polarization.

Two equilibrium dialysis experiments were performed. In the first 1 $\mathrm{ml}$ of Krebs buffer was added to the chambers on each side of the membrane. In the second experiment $1 \mathrm{ml}$ of Krebs buffer was added to one chamber and $1 \mathrm{ml}$ of normal human serum to the other. Tracer amounts of ${ }^{3} \mathrm{H}-\mathrm{DS}$, calculated to result in a final concentration similar to that observed in serum in vivo, was added to Krebs buffer in one chamber in the first experiment, and to serum in the second experi-

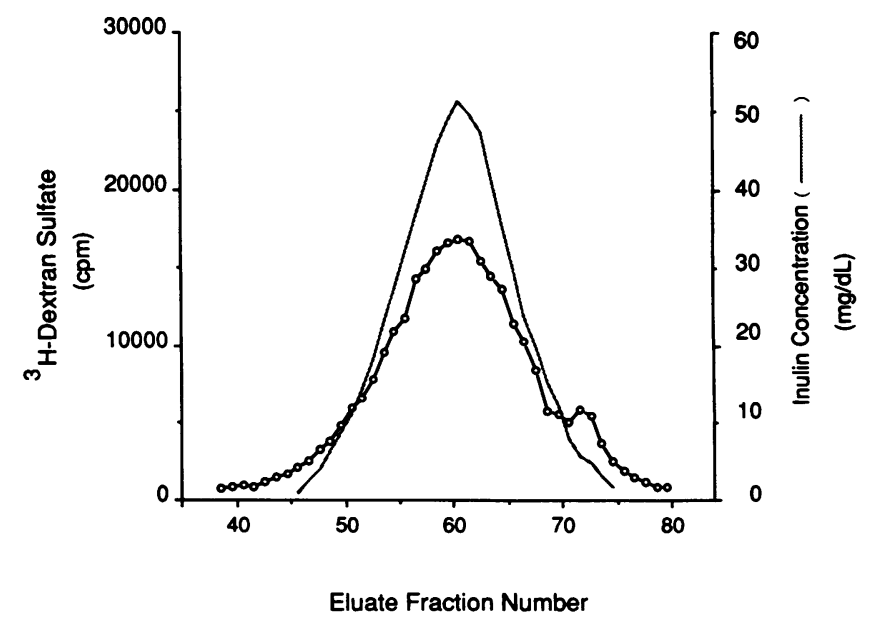

Figure 1. Sephadex G-75 chromatogram of infusate ${ }^{3} \mathrm{H}-\mathrm{DS}(\mathrm{O})$ and inulin $(\cdots)$ reveal a similar size distribution. The peak radius for each marker approximates $16 \AA$. 
ment. Each chamber was then sampled after $30 \mathrm{~min}$, and 1, 15, 23, and $50 \mathrm{~h}$. Equilibration was achieved after $50 \mathrm{~h}$ only in the Krebs buffer experiment (Fig. 2). In the serum experiment a steady state was reached after $15 \mathrm{~h}$ with $69 \%$ of the ${ }^{3} \mathrm{H}$-DS remaining on the serum side and $31 \%$ on the Krebs buffer side of the membrane. Dividing the latter (free) by the former (free + bound) indicates that only $45 \%$ of the ${ }^{3} \mathrm{H}-\mathrm{DS}$ was not protein bound.

For the ultrafiltration experiments tracer amounts of ${ }^{3} \mathrm{H}-\mathrm{DS}$ were added to Krebs buffer, Krebs buffer containing human albumin in concentrations varying from 0.01 to $40 \mathrm{mg} / \mathrm{ml}$, nephrotic and normal urine, and nephrotic and normal serum. $10 \mathrm{ml}$ of each solution was placed in the sample chamber and subjected to an ultrafiltration pressure of $50-100 \mathrm{mmHg}$ for $30 \mathrm{~min}$, yielding ultrafiltrate volumes which were $15-20 \%$ of the initial sample volume. Each experiment was repeated after addition of nonisotopic DS in amounts equimolar with the albumin in each solution. Whereas $90 \%$ of the ${ }^{3} \mathrm{H}$-DS was recovered in the ultrafiltrate of pure Krebs buffer, recovery fell to between $30 \%$ and $40 \%$ in the albumin-containing Krebs solutions. Similarly, recovery of ${ }^{3} \mathrm{H}$-DS in ultrafiltrate of normal urine was $86 \%$, but corresponding recovery from nephrotic urine or normal or nephrotic serum, varied from only $30 \%$ to $40 \%$. Addition of an excess of cold DS to each of the foregoing solutions restored recovery to $\sim 90 \%$ (Fig. 3 ).

To examine the effects of molecular radius on protein binding, ${ }^{3} \mathrm{H}$-DS added to Krebs buffer or human serum was separated into four fractions by elution from the Sephadex G75 columns and the ultrafiltration experiments were then repeated on each eluate. The recovery of ${ }^{3} \mathrm{H}$-DS from eluted fractions in Krebs buffer of varying molecular radius varied from $85 \%$ to $100 \%$. In contrast, recovery of each fraction from serum varied with the molecular radius of the ${ }^{3} \mathrm{H}-\mathrm{DS}$ in the fraction, declining progressively from $78 \%$ for the $10 \AA$ radius fraction to only $13 \%$ for the $24 \AA$ fraction (Fig. 4). That this phenomenon most likely represents size-dependent binding of DS to serum protein was confirmed by restoration of recovery to levels observed with Krebs buffer when an excess of cold DS was added to each serum sample prior to chromatographic separation (Fig. 4).
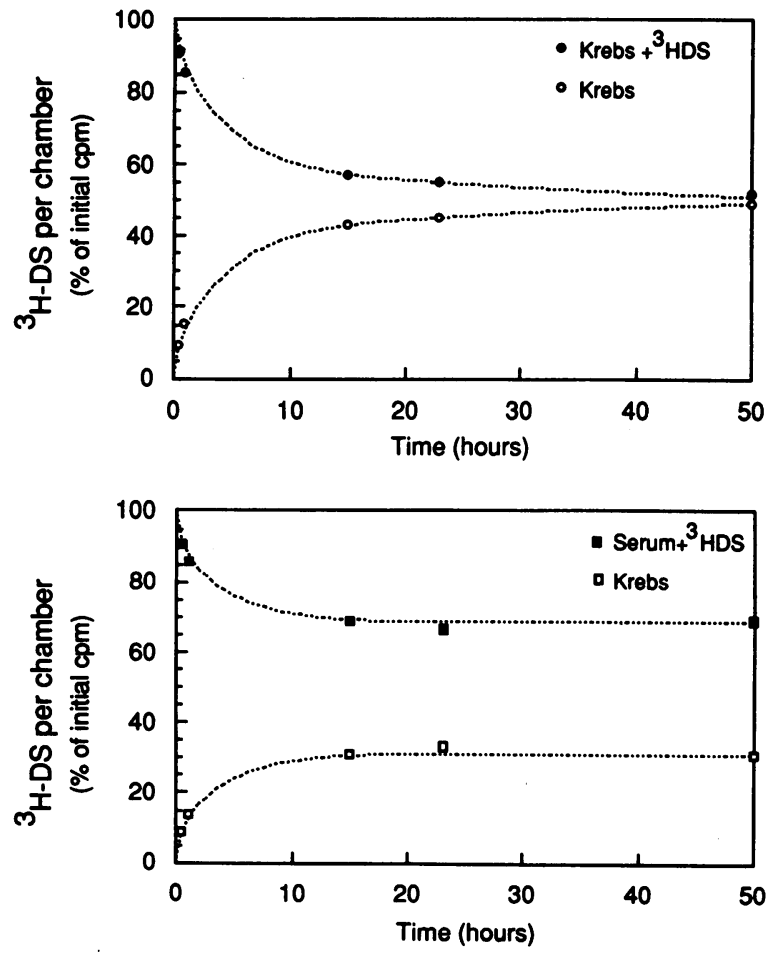

Figure 2. Equilibrium dialysis experiments where Krebs buffer (upper panel) or serum spiked with ${ }^{3} \mathrm{H}-\mathrm{DS}$ (lower panel) has been dialyzed against Krebs buffer alone.

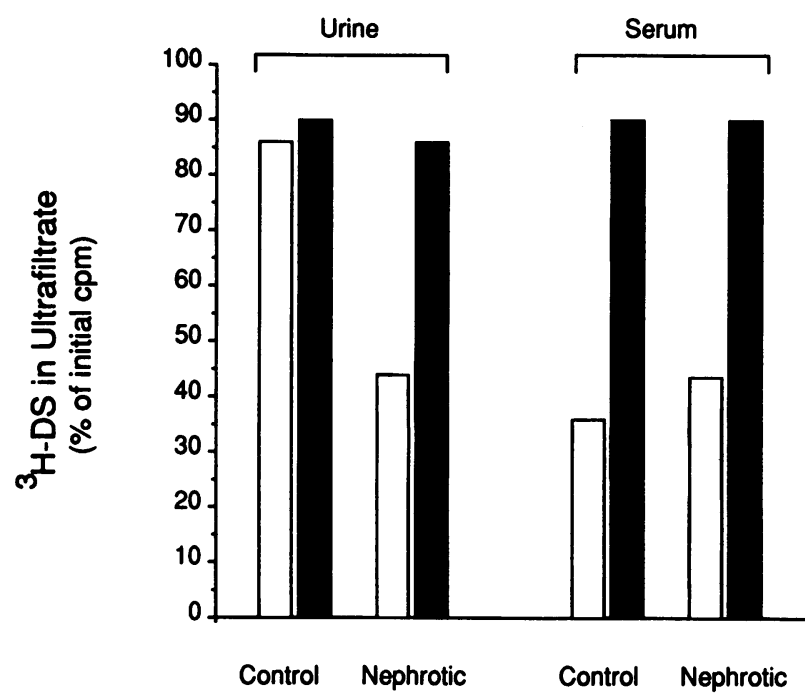

Figure 3. Recovery of ${ }^{3} \mathrm{H}-\mathrm{DS}$ in ultrafiltrates of normal or nephrotic urine (left) and normal or nephrotic serum (right, open bars). Addition of excess cold DS before filtration restored recovery of ${ }^{3} \mathrm{H}$-DS in ultrafiltrates to $\sim 90 \%$ in both fluids (solid bars).

Determination of $\theta$ for dextran sulfate. In light of our finding that DS is indeed extensively protein-bound we used the stirred-cell ultrafiltration apparatus to prepare $\sim 2 \mathrm{ml}$ of ultrafiltrate from $10 \mathrm{ml}$ of plasma ( $5 \mathrm{ml}$ from each plasma sample bracketing the first urine collection ). We calculate the fraction of ${ }^{3} \mathrm{H}$-DS bound to circulating albumin to account for only $\leq 1 \%$ of observed specific activity in normal or nephrotic urine, indicating that the extensive binding of ${ }^{3} \mathrm{H}-\mathrm{DS}$ to protein in nephrotic urine occurred along the nephron or in the collecting system. We accordingly eluted the ultrafiltrate of plasma along with unfiltered urine containing an excess of cold DS from Sephadex G75 columns to isolate the peak ${ }^{3} \mathrm{H}$-DS fraction from each fluid. We then determined $\theta$ for this narrow DS fraction using the equation:

$\theta_{\mathrm{DS}}=(U / P F)_{\mathrm{DS}} \div(U / P)_{\text {inulin }}$

where $(U / P F)_{\mathrm{DS}}$ is the specific activity ratio of unfiltered urine-to-

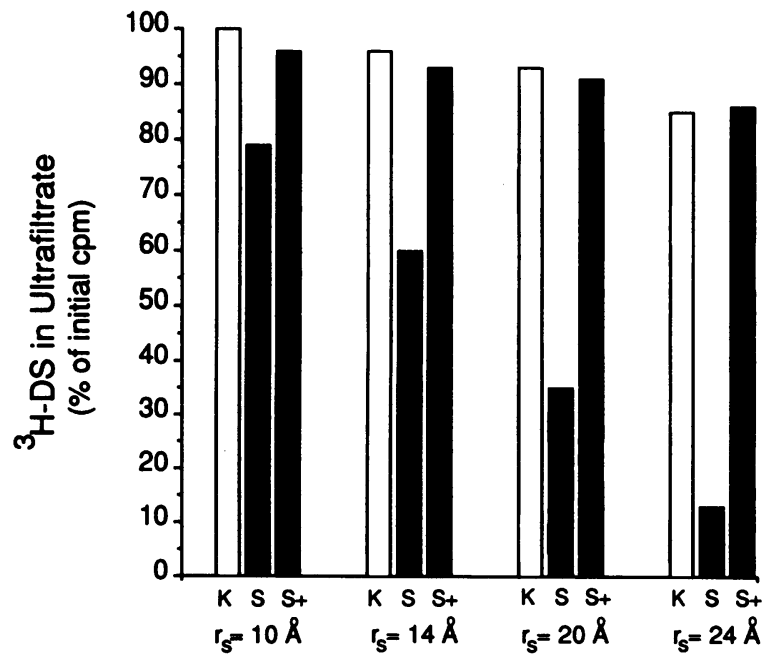

Figure 4. Recovery of ${ }^{3} \mathrm{H}$-DS from ultrafiltrates of Krebs buffer ( $K$, open bar) and serum ( $S$, solid bar) after separation by GPC into four fractions of discrete radius. Addition of excess cold DS to serum before filtration restores recovery in fractions of the latter $(S+$, stippled bars) to values similar to those in corresponding Krebs' fractions. 
plasma filtrate; and $(U / P)_{\text {inulin }}$ is the urine-to-plasma concentration ratio for inulin.

Data and statistical analysis. To characterize the size-selective properties of the glomerular filtration barrier, we applied the $\theta$ for uncharged dextrans in the $24-60 \AA$ radius interval to a heteroporous membrane model that has been described in detail previously (15). In this model, the major portion of the capillary wall is assumed to be perforated by restrictive, cylindrical pores of identical radius $\left(r_{0}\right)$. The model assumes that there exists in addition a parallel shunt pathway that does not discriminate on the basis of dextran size (up to $60 \AA$ radius), and through which passes a small fraction of the filtrate volume. The shunt pathway is characterized by a parameter, $\omega_{0}$, which governs the fraction of the total filtrate volume passing through this nonrestrictive portion of the membrane. In addition to $r_{0}$ and $\omega_{0}$ the membrane barrier to filtration of water and uncharged macromolecules is characterized by an ultrafiltration coefficient $\left(K_{\mathrm{f}}\right)$, the product of effective hydraulic permeability and total glomerular capillary surface area (for two kidneys). The approach used for calculating these intrinsic membrane parameters separates their effects on fractional dextran clearance from those of purely hemodynamic changes (15). An additional value that can be derived from this membrane model (15), is the clearance of a hypothetical macromolecule that is attributable to the shunt pathway $\left(\theta_{\infty}\right)$. Because the luminal concentration of a retained macromolecule will increase with distance along the glomerular capillaries as water is removed by ultrafiltration, $\theta_{\infty}$ slightly exceeds the fraction of filtrate volume passing through the shunt pathway. By deriving $\theta_{\infty}$ and comparing it to the corresponding fractional clearances of albumin and IgG in the nephrotic patients of the parallel study, we have attempted to elucidate whether the magnitude of the urinary losses of these proteins can be attributed solely to the postulated shunts.

The significance of differences between the two groups studied with dextran sulfate was evaluated by a two-tailed unpaired Student's $t$ test. An analysis of variance and Scheffe's test were used to evaluate the significance of differences among nephrotic patients with either minimal change or membranous nephropathy and healthy controls in the parallel study of uncharged dextran sieving. Most group values are expressed as the mean \pm standard error. The exceptions are group data with a skewed distribution, which are expressed as a median and a range.

Table I. Glomerular Function in DS Sieving Study

\begin{tabular}{|c|c|c|}
\hline & $\begin{array}{l}\text { Nonproteinuric } \\
\quad(n=11)\end{array}$ & $\begin{array}{l}\text { Nephrotic } \\
(n=11)\end{array}$ \\
\hline $\begin{array}{l}\text { Glomerular filtration rate } \\
\left(\mathrm{ml} / \mathrm{min} \text { per } 1.73 \mathrm{~m}^{2}\right)\end{array}$ & $97 \pm 6$ & $45 \pm 13^{\ddagger}$ \\
\hline $\begin{array}{l}\text { Renal plasma flow } \\
\qquad\left(\mathrm{ml} / \mathrm{min} \text { per } 1.73 \mathrm{~m}^{2}\right)\end{array}$ & $507 \pm 36$ & $399 \pm 77$ \\
\hline Filtration fraction & $0.19 \pm 0.01$ & $0.13 \pm 0.01^{\ddagger}$ \\
\hline $\begin{array}{l}\text { Plasma oncotic pressure } \\
\qquad(m m H g)\end{array}$ & $24.2 \pm 0.6$ & $13.8 \pm 1.3^{\ddagger}$ \\
\hline $\begin{array}{l}\text { Albumin excretion rate* } \\
\qquad(\mu \mathrm{g} / \mathrm{min})\end{array}$ & $\begin{array}{l}6 \\
(1-26)\end{array}$ & $\begin{array}{c}5557^{\ddagger} \\
(1,276-14,322)\end{array}$ \\
\hline $\begin{array}{l}\text { IgG excretion rate* } \\
(\mu \mathrm{g} / \mathrm{min})\end{array}$ & $\begin{array}{l}2 \\
(1-4)\end{array}$ & $\begin{array}{c}220^{\ddagger} \\
(77-1,946)\end{array}$ \\
\hline $\begin{array}{l}\text { Fractional albumin clearance* } \\
\left(\times 10^{-5}\right)\end{array}$ & $\begin{array}{c}0.2 \\
(0.1-1)\end{array}$ & $\begin{array}{c}879^{\ddagger} \\
(79-7,328)\end{array}$ \\
\hline $\begin{array}{l}\text { Fractional IgG clearance* } \\
\qquad\left(\times 10^{-5}\right)\end{array}$ & $\begin{array}{c}0.1 \\
(0.1-0.5)\end{array}$ & $\begin{array}{c}268^{\ddagger} \\
(16-4,074)\end{array}$ \\
\hline
\end{tabular}

* Values are median (range). ${ }^{\ddagger} P<0.01$ vs. controls.

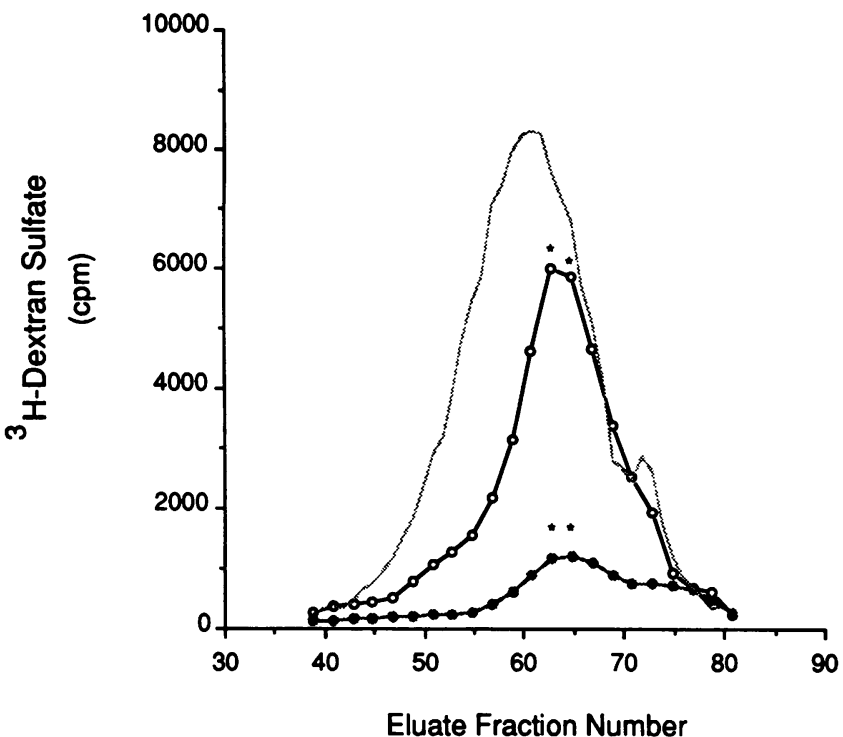

Figure 5. Distribution of ${ }^{3} \mathrm{H}-\mathrm{DS}$ in representative chromatograms of urine $(0)$ and plasma ultrafiltrate $(\bullet)$ is different from that in chromatogram of ${ }^{3} \mathrm{H}-\mathrm{DS}$ in infusate $(-)$. The largest DS molecules are underrepresented in urine and plasma ultrafiltrate, reflecting size-dependent protein binding and glomerular filtration. The two peak fractions (corresponding to a radius of $\sim 15 \AA$ ) in urine and plasma ultrafiltrate have been used to calculate $\theta$ for DS.

\section{Results}

Dextran sulfate sieving. Neither GFR and its determinants nor the magnitude of urinary protein losses differed between the eight healthy volunteers and the three patients with minimal change nephropathy which had entered a complete remission. For purposes of statistical analysis, we have thus combined these two categories into a single nonproteinuric group. Their glomerular function is compared to that of the nephrotic group in Table I. In addition to urinary excretion rates and fractional clearances of albumin and IgG that were larger by two to three orders of magnitude, the nephrotic group differed from the nonproteinuric group in that the GFR, filtration fraction and plasma oncotic pressure were all significantly depressed.

The peak radius of DS in plasma ultrafiltrate and urine was shifted to slightly smaller size than in infusate due to a combination of protein binding and size dependence in glomerular filtration (Fig. 5). Only the specific activity of the 2 peak eluted fractions of ${ }^{3} \mathrm{H}$-DS in plasma ultrafiltrate was sufficiently above background to be accurately determined in every case, varying between 400 and $2,300 \mathrm{cpm}$. We accordingly used the average value of these two peak fractions (corresponding to a molecular radius of $15 \AA$ ) and the corresponding aligned fractions in urine to calculate the $\theta$ for DS. The $\theta$ for this $15 \AA$ radius DS molecule averaged $0.68 \pm 0.03$ in nonproteinuric subjects. For nephrotic subjects by contrast, corresponding $\theta$ for the $15 \AA$ radius DS was elevated significantly to $0.95 \pm 0.05(P<0.001)$ (Table II).

Uncharged dextran sieving. The measures of renal function in both the nephrotic and nonproteinuric groups in the parallel study were similar to the values listed for the corresponding DS-infused groups and are summarized in Table III. As before, 
Table II. Sieving Coefficients ( $\theta)$ for $15 \AA$ AS

\begin{tabular}{|c|c|c|c|c|c|}
\hline \multicolumn{3}{|c|}{ Nonproteinuric } & \multicolumn{3}{|c|}{ Nephrotic } \\
\hline Case & Category & $\theta$ & Case & Category & $\theta$ \\
\hline 1 & healthy control & 0.68 & 1 & membranous & 0.93 \\
\hline 2 & healthy control & 0.64 & 2 & membranous & 0.76 \\
\hline 3 & healthy control & 0.49 & 3 & membranous & 1.06 \\
\hline 4 & healthy control & 0.68 & 4 & membranous & 1.04 \\
\hline 5 & healthy control & 0.80 & 5 & membranous & 1.02 \\
\hline 6 & healthy control & 0.79 & 6 & $\mathrm{MCN}$ & 0.63 \\
\hline 7 & healthy control & 0.67 & 7 & $\mathrm{MCN}$ & 1.04 \\
\hline 8 & healthy control & 0.81 & 8 & $\mathrm{MCN}$ & 1.09 \\
\hline 9 & remission $\mathrm{MCN}$ & 0.55 & 9 & $\mathrm{MCN}$ & 1.02 \\
\hline 10 & remission $\mathrm{MCN}$ & 0.66 & 10 & $\mathrm{MCN}$ & 1.09 \\
\hline 11 & remission $\mathrm{MCN}$ & 0.75 & 11 & $\mathrm{MCN}$ & 0.77 \\
\hline Mean $( \pm$ SE) & & $0.68 \pm 0.03$ & & & $0.95 \pm 0.05^{*}$ \\
\hline
\end{tabular}

MCN, minimal change nephropathy. ${ }^{*} P$ value $=0.0001$ vs. nonproteinuric.

nephrotic range proteinuria was accompanied by depression of the GFR, filtration fraction, and oncotic pressure (Table III). The magnitude of glomerular injury tended to be greater in the subset with membranous nephropathy than in the subset with minimal change nephropathy, however. The GFR was significantly lower, averaging $54 \pm 6$ vs. $75 \pm 9 \mathrm{ml} / \mathrm{min}$ per $1.73 \mathrm{~m}^{2}$, respectively $(P<0.05)$. Judged by higher median values for the fractional clearances of albumin (700 vs. $491 \times 10^{-5}, P$ $=\mathrm{NS})$ and $\mathrm{IgG}\left(109 \mathrm{vs.} 41 \times 10^{-5}, P=\mathrm{NS}\right)$, glomerular permeability to proteins tended to be more enhanced in membranous than in minimal change nephropathy.

A qualitatively similar alteration of the uncharged dextran sieving profile was observed in each category of nephrotic glomerular injury (Fig. 6). Compared to control values, the $\theta$ for

Table III. Glomerular Function in Parallel Uncharged Dextran Sieving Study

\begin{tabular}{lcc}
\hline & $\begin{array}{c}\text { Nonproteinuric } \\
(n=19)\end{array}$ & $\begin{array}{c}\text { Nephrotic } \\
(n=47)\end{array}$ \\
\hline $\begin{array}{c}\text { Glomerular filtration rate } \\
\left(\mathrm{ml} / \text { min per } 1.73 \mathrm{~m}^{2}\right)\end{array}$ & $108 \pm 3$ & \\
Renal plasma flow & & $63 \pm 5^{\ddagger}$ \\
$\left(\mathrm{ml} /\right.$ min per $\left.1.73 \mathrm{~m}^{2}\right)$ & $584 \pm 25$ & $628 \pm 61$ \\
Filtration fraction & $0.19 \pm 0.01$ & $0.12 \pm 0.01^{\ddagger}$ \\
Plasma oncotic pressure & & \\
$(m m H g)$ & $22.8 \pm 0.4$ & $13.9 \pm 0.6^{\ddagger}$ \\
Albumin excretion rate* & 6 & $5827^{\ddagger}$ \\
$\quad(\mu g /$ min $)$ & $(2-32)$ & $(2,200-26,300)$ \\
IgG excretion rate* & 1.3 & $234^{\ddagger}$ \\
$(\mu g /$ min $)$ & $(0.2-4)$ & $(8-2,719)$ \\
Fractional albumin clearance* & 0.3 & $584^{\ddagger}$ \\
$\left(\times 10^{-5}\right)$ & $(0.1-1)$ & $(88-8,880)$ \\
Fractional IgG clearance* & 0.1 & $93^{\ddagger}$ \\
$\left(\times 10^{-5}\right)$ & $(0.1-0.4)$ & $(5-9,367)$
\end{tabular}

* Values are median (range). ${ }^{\ddagger} P<0.01$ vs. controls. low radius dextrans ( $<50 \AA$ radius) was depressed, whereas $\theta$ for large nearly impermeant dextrans of $>52 \AA$ was significantly elevated. In keeping with the higher values for fractional protein clearances in membranous than minimal change nephropathy, the values for $\theta$ over the entire range of molecular radii examined tended to be higher in the former (Fig. 6).

We used the $\theta$ for dextran, measured GFR, renal plasma flow and plasma oncotic pressure and an assumed value for the glomerular transcapillary hydraulic pressure difference $(\Delta P)$ of $35 \mathrm{mmHg}$ to compute membrane parameters for each member of the two nephrotic categories and the control group (Table

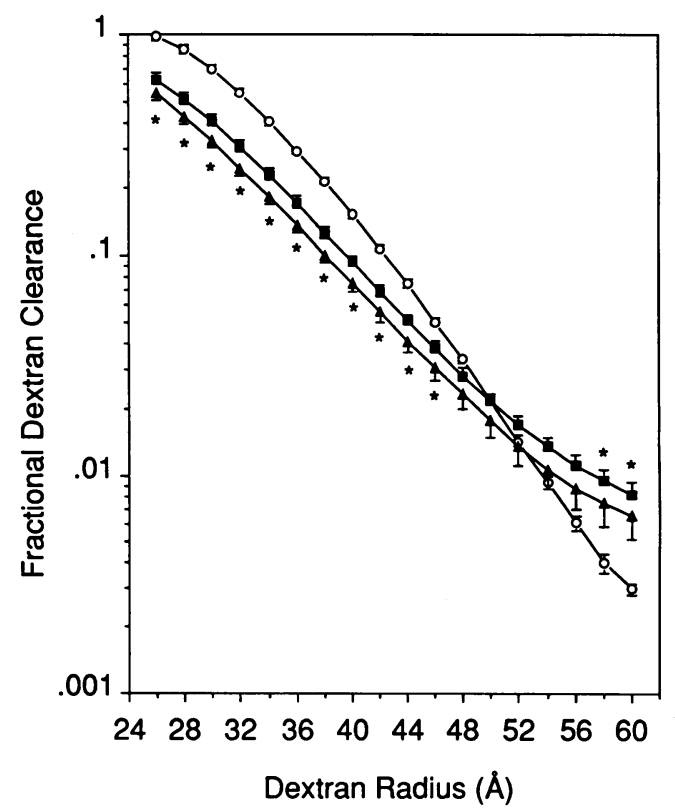

Figure 6. Fractional dextran clearance profiles in the parallel groups of healthy controls ( $(0), \operatorname{MCN}(\triangle)$, and $\mathrm{MN}(\bullet)$. An asterisk indicates significant differences between the values for $\theta$ in the two nephrotic groups vs. controls $(P<0.01)$. 
Table IV. Membrane Parameters in Unchanged Dextran Sieving Study

\begin{tabular}{lccc}
\hline & $\begin{array}{c}\text { Nonproteinuric } \\
(n=19)\end{array}$ & $\begin{array}{c}\text { MCN } \\
(n=20)\end{array}$ & $\begin{array}{c}\text { MN } \\
(n=27)\end{array}$ \\
\hline $\begin{array}{c}\text { Ultrafiltration coefficient, } \\
K_{\mathrm{f}}(\mathrm{ml} /\{\mathrm{min} \cdot \mathrm{mm} \mathrm{Hg}\}\end{array}$ & & & \\
$\quad$ per $\left.1.73 \mathrm{~m}^{2}\right)$ & $14.7 \pm 1.6^{*}$ & $4.6 \pm 0.7^{\ddagger}$ & $3.0 \pm 0.3^{\ddagger}$ \\
$\begin{array}{l}\text { Restrictive pore radius } \\
\left(r_{0}, \AA\right)\end{array}$ & $57.2 \pm 0.2^{*}$ & $52.3 \pm 0.5^{\ddagger}$ & $53.9 \pm 0.5^{\S}$ \\
$\begin{array}{l}\text { Shunt parameter } \\
\left(\omega_{0} \times 10^{-3}\right)\end{array}$ & $1.3^{*}$ & $5.1^{\ddagger}$ & $6.5^{\ddagger}$ \\
& $(0.6-2.8)$ & $(0.4-40)$ & $(2.7-32.3)$ \\
Fractional clearance via & $3.6^{*}$ & $7.3^{\ddagger}$ & $7.9^{\S}$ \\
shunt $\left(\theta_{\infty} \times 10^{-3}\right)$ & $(2-11.8)$ & $(1.1-35.0)$ & $(4.7-38.8)$ \\
& & & \\
\hline
\end{tabular}

Means that are not different are represented with the same symbol.

IV). Computed $K_{\mathrm{f}}$ was depressed by $80 \%$ in membranous nephropathy and by $69 \%$ in minimal change nephropathy, indicating a severe loss of ultrafiltration capacity in each disorder. The radius of restrictive pores was also lowered in each category of the nephrotic syndrome, on average by 3 and $5 \AA$, respec-

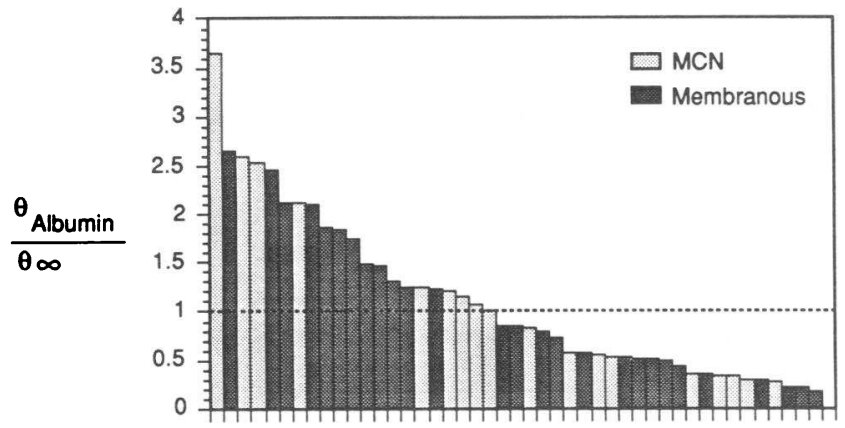

Individual Nephrotic Patients

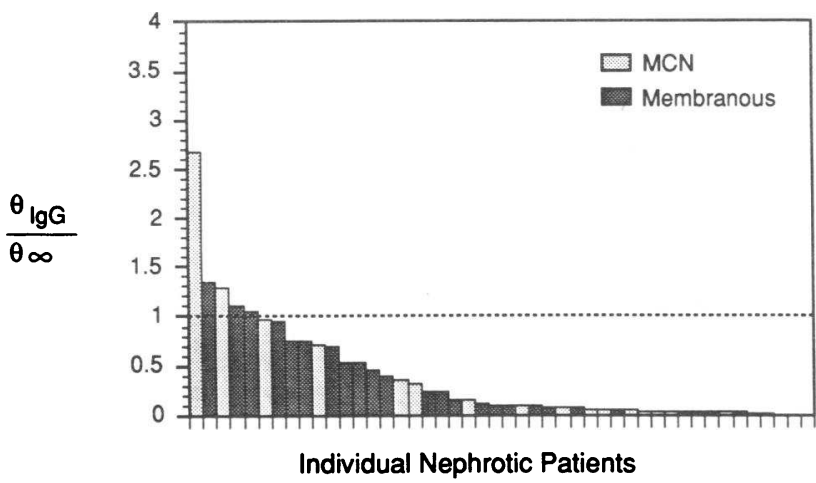

Figure 7. The ratio of fractional protein clearance-to- $\theta_{\infty}$ in individual nephrotic subjects of the parallel study. Albumin is shown in the upper panel and IgG in the lower panel. Solid bars represent patients with membranous and light stippled bars patients with minimal change nephropathy. The dashed horizontal lines indicate equality of the fractional protein clearance with $\theta_{\infty}$, the fractional clearance of a hypothetical macromolecule through the shunt pathway. tively (Table IV). However, judged by an elevation of the median value for $\omega_{0}$, which reached fivefold in membranous nephropathy and fourfold in minimal change nephropathy, a considerably larger fraction of filtrate volume permeated the shuntlike pores in each nephrotic subset than in the nonproteinuric control subjects (Table IV).

The foregoing membrane parameters were used to calculate the fractional clearance of a hypothetical macromolecule attributable to the shuntlike pores (Table IV). This quantity is denoted by $\theta_{\infty}$ and neglects tubule reabsorption. The relationship between the fractional clearance of each protein and $\theta_{\infty}$ in individual nephrotic subjects of the parallel study is illustrated in Fig. 7. Judged by the fractional clearance -to- $\theta_{\infty}$ ratio, the value for $\theta_{\infty}$ is similar to or in excess of the corresponding fractional IgG clearance in almost all instances, suggesting that transmembrane shunting can account for the level of immunoglobulinuria in these two nephrotic disorders. In contrast, the fractional albumin clearance exceeded $\theta_{\infty}$ in a substantial fraction $(21 / 47)$ of the nephrotic subjects, regardless of whether they were suffering from membranous or minimal change nephropathy (Fig. 7). Recalling that a fraction of filtered albumin is reabsorbed, this finding suggests that the smaller restrictive pores must also be permeable to albumin in at least some nephrotic patients with minimal change or membranous nephropathy.

That enhanced permeability to albumin of restrictive pores could be a consequence of impaired electrostatic retardation is suggested by a comparison of $\theta$ for the $15 \AA$ radius DS with that of $\theta$ for the smallest assayable molecule of uncharged dextran (18-22Å in radius) in the parallel study (Fig. 8). Because all

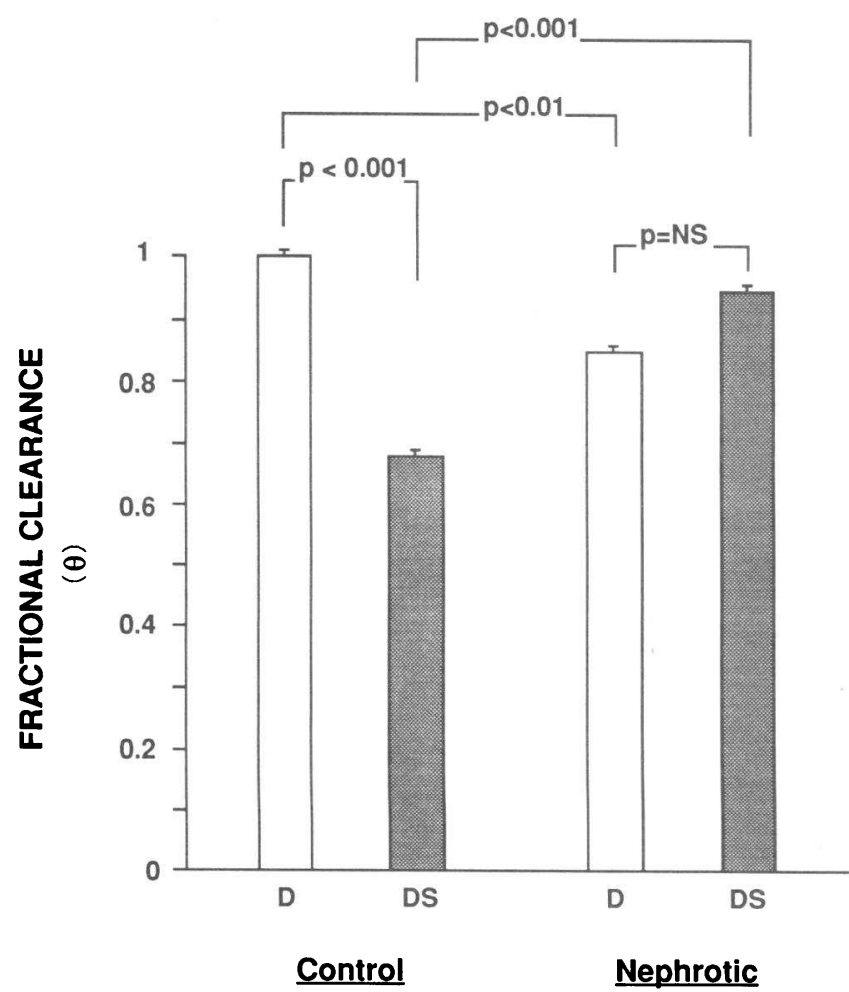

Figure 8 . The $\theta$ for anionic dextran sulfate ( $D S$, solid bars) and neutral dextran of similar radius $(18-22 \AA, D$, open bars $)$ in nonproteinuric controls (left) and nephrotic subjects (right). 
assayable dextran molecules of $<26 \AA$ were unrestricted by the GCW of the control subjects of the parallel study (Fig. 6), we infer that $\theta$ for an uncharged dextran of $15 \AA$ radius must also be 1.0. For the nonproteinuric groups, the $\theta$ for DS was significantly lower than the corresponding $\theta$ for uncharged dextran $0.68 \pm 0.03$ vs. $1.00 \pm 0.04$, respectively $(P<0.001)$. For the nephrotic groups by contrast, the respective values of $\theta$ for DS and uncharged dextran were similar, $0.95 \pm 0.05$ vs. $0.85 \pm 0.03$, respectively $(P=\mathrm{NS})$. Thus, unlike the healthy $\mathrm{GCW}$, the nephrotic GCW appears not to discriminate between anionic and uncharged dextran molecules of similar radius.

\section{Discussion}

Numerous studies using experimental animals have shown that the normal glomerular capillary wall is a charge-selective barrier. In rats and dogs, values of $\theta$ for various anionic macromolecules have been shown to be lower than $\theta$ for neutral macromolecules of similar size and chemical structure (5, 21-30), which in turn are lower than values of $\theta$ for otherwise similar cationic macromolecules $(24-26,28,29,31)$. In other words, transport of negatively charged macromolecules is hindered, and that of positively charged macromolecules is enhanced, relative to uncharged macromolecules. The present results with DS provide the first direct evidence that the glomerular capillary wall in humans normally exhibits charge selectivity similar to that reported for experimental animals.

DS was chosen as the charged probe because, like dextran, it has been shown not to be reabsorbed $(5,23)$. Accordingly, its fractional urinary clearance equals its sieving coefficient, or Bowman's space-to-plasma concentration ratio. By contrast, drawing conclusions about glomerular barrier properties from the urinary excretion of albumin is made difficult by the fact that the fractional reabsorption of albumin normally approaches unity $(2,3)$, and can be estimated in humans only indirectly (32). An important disadvantage in the use of DS, not previously recognized, is its tendency to bind to plasma proteins. For the polydisperse preparation used here, only $\sim 45 \%$ of the DS in serum was not protein bound. In concurrent studies of the same DS preparation, the extent of binding to proteins in rat plasma ( $48 \%$ not bound) was found to be similar (33). The situation is further complicated by the fact that the percentage bound depends on the molecular radius of the DS, increasing as molecular radius increases. Thus size exclusion chromatography of an ultrafiltrate of plasma and of urine is necessary in order to determine the true sieving coefficient for DS.

The failure to account for protein binding in earlier studies using DS makes the quantitative interpretation of those results difficult. However, it must be emphasized that the current findings are qualitatively the same, namely that DS is restricted relative to neutral dextran of similar size. Moreover, similar glomerular selectivity has been demonstrated towards proteins of similar size but varying charge in studies where urinary clearances have been adjusted for reabsorption by measuring accumulation of the test protein in renal tissue. This approach has been employed in rats using neutral, anionic, and cationic forms of horseradish peroxidase $(24-26,28,29)$ and anionic and neutral forms of bovine serum albumin (34).

It has been proposed that the charge selectivity of the glo- merular capillary can be attributed to an electrostatic potential difference created by fixed negative charges within the capillary wall, as in a Donnan equilibrium (16). In this model the capillary wall is represented as an equivalent homogeneous membrane containing a uniform concentration, $C_{m}$, of fixed negative charges. According to this simplified approach, the only property of a test macromolecule which affects its electrostatic interaction with the membrane is its total charge, or effective valence, $z$. For the $15 \AA$ radius DS, we calculate that $z=-11$, based on an estimate of the number of sulfate groups and a correction for counterion condensation (see Appendix). Using the values of GFR, renal plasma flow, and oncotic pressure in Table I, an assumed value of $\Delta P=35 \mathrm{mmHg}$, the effective pore radius in Table IV, and $\theta=0.68$, we obtain $C_{\mathrm{m}}=90 \mathrm{meq} / \mathrm{liter}$ for healthy humans. Applying the same approach to the recent data for normal Munich Wistar rats (33), where protein-binding was corrected for, and $\theta=0.46$ for $r_{\mathrm{s}}=18 \AA$, we calculate ${ }^{2}$ that $C_{\mathrm{m}}=60 \mathrm{meq} /$ liter. The present estimates of $C_{\mathrm{m}}$ from dextran sulfate data are about one-half those reported previously (35). This is primarily because a different method was used to estimate $z$ for DS, and not because of any large difference between the values of $\theta$ used here and those reported in earlier studies. It is interesting to note that the present estimate of $C_{\mathrm{m}}$ for rats agrees with the value calculated from data reported for neutral and charged species of horseradish peroxidase (35). It must be emphasized that, because this simplified model does not incorporate any details of where the fixed charge resides, and does not account for the effects of molecular size or shape on electrostatic interactions, the values of $C_{\mathrm{m}}$ do not necessarily correspond to actual charge concentrations within any given part of the capillary wall. Like values of effective pore radius, they are useful for making comparisons within the context of a particular model.

In addition to furnishing the first direct evidence that the human glomerular capillary wall is normally charge-selective, the present results also provide the first demonstration that this charge-selectivity is impaired in nephrotic humans. For the nephrotic groups studied there was no significant difference between $\theta$ for DS and $\theta$ for uncharged dextran of similar size. Losses of charge-selectivity have been demonstrated also in several rat models of glomerular injury, including nephrotoxic serum nephritis (5), puromycin aminonucleoside nephrosis (17), and renal ablation $(24,33)$. As already discussed, the loss of charge selectivity in the nephrotic individuals provides an attractive explanation for the fact that the rate of albumin excretion often exceeded what could be accounted for by postulating the emergence of large, shuntlike pores (Fig. 7). In other words, the magnitude of the defect in glomerular size selectivity, as measured by the increased filtration of large, neutral dextrans, was insufficient in many cases to explain the extent to which albuminuria was enhanced. Because albumin is a polyanion, a reduction in the fixed negative charge associated

2. The mean value for systemic protein concentration reported by Mayer et al. (33) was $C_{\mathrm{A}}=4.7 \mathrm{~g} / \mathrm{dl}$. For the other inputs necessary in the charge model for which data were not reported, we chose values representative of a large number of studies in normal euvolemic Munich-Wistar rats, as summarized by Maddox et al. (35): effective pore radius, $r_{0}=50 \AA$; glomerular plasma flow rate, $Q_{\mathrm{A}}=150 \mathrm{nl} / \mathrm{min}$; glomerular ultrafiltration coefficient, $K_{\mathrm{f}}=5.6 \mathrm{nl} / \mathrm{min} / \mathrm{mmHg}$; and glomerular transcapillary pressure difference, $\Delta P=35 \mathrm{mmHg}$. 
with the small-pore part of the membrane could greatly enhance its filtration. According to the aforementioned electrostatic model, a reduction in $C_{\mathrm{m}}$ from $90 \mathrm{meq} /$ liter to 0 would result in a hundred fold increase in albumin filtration (35).

Given the results for dextran and DS, the albuminuria observed in minimal change and membranous nephropathy probably reflects a combination of size-selective and charge-selective defects. However, it is not yet possible to calculate the relative importance of the two types of defects. Studies in the rat have shown that, for a given value of molecular radius, dextran passes through the glomerular capillary wall more readily than does another uncharged test macromolecule, Ficoll $(6,36)$. Diffusion studies with synthetic membranes suggest that Ficoll behaves like the neutral, spherical molecule envisioned in the theory of hindered transport through pores, whereas transmembrane diffusion of dextran is more rapid than expected from its molecular radius $(37,38)$. This facilitation of dextran transport implies that the use of dextran data to evaluate membrane pore parameters will tend to overestimate the effective pore size (36). It is possible that the contribution of the shunt pathway, as reflected by the value of $\theta_{\infty}$, is also overestimated by using dextran. Thus, whereas the dextran data in the nephrotic subjects clearly demonstrate that there is a size-selective defect, studies with Ficoll or other more ideal test macromolecules are needed to better establish the precise magnitude of that defect. The finding that dextran sulfate binds to plasma proteins makes it clear that future studies would benefit also from the development of a more ideal marker for glomerular charge selectivity.

\section{Appendix}

Estimation of molecular charge for DS. The measured sulfur content of $13.5 \%$ by weight indicates that the sodium dextran sulfate had an average of 1.2 sulfate groups (1.2 negative charges) per glucose monomer. In the absence of suitable dextran sulfate standards of known molecular weight $(M)$, which would have permitted determination of $M$ for our material by size-exclusion chromatography, we assume that our DS had the same number of monomers $(n)$ as a neutral dextran molecule of equivalent Stokes-Einstein radius, $r_{\mathbf{s}}$. Using a recently reported correlation between $r_{\mathrm{s}}$ and $M$ for neutral dextran (36), $M_{\mathrm{D}}=2600$ for $r_{\mathrm{s}}=15 \AA$ and therefore $n_{\mathrm{D}}=16$. Assuming $n_{\mathrm{DS}}=n_{\mathrm{D}}$ and accounting for the difference in monomer mass ( 284 vs. 162 ), $M_{\mathrm{Ds}}=4500$ for $r_{\mathrm{s}}=15 \AA$.

With $n_{\mathrm{DS}}=16$ and an average of 1.2 sulfate groups per monomer, the total stoichiometric charge is $-(1.2)(16)$ $=-19$. However, it has been found that if the stoichiometric charge density of a linear polyelectrolyte exceeds a certain limit, counterions are so strongly attracted to the polymer that they neutralize any additional charge. This phenomenon is termed "counterion condensation." According to the simplest model for counterion condensation, developed by Manning (39), if the polyelectrolyte is represented as a series of charges arranged in a line, the average spacing between charges cannot be less than the Bjerrum length

$L_{\mathrm{B}}=\frac{e^{2}}{4 \pi \varepsilon k_{\mathrm{B}} T}$,

where $e$ is the electronic charge, $\varepsilon$ is the permittivity, $k_{\mathrm{B}}$ is Boltz- mann's constant, and $T$ is absolute temperature. For water at $37^{\circ} \mathrm{C}, L_{\mathrm{B}}=7.25 \AA$, which exceeds the length of a glucose monomer $\left(L_{\mathrm{M}}=5.2 \AA\right)$ and the average spacing of sulfate groups on DS $(5.2 \AA / 1.2=4.3 \AA)$. Thus, the effective charge of DS will be less than its stoichiometric charge. It follows that the effective charge $z$ of DS is $|z|=n_{\mathrm{DS}} L_{\mathrm{M}} / L_{\mathrm{B}}=0.72 n_{\mathrm{DS}}$. For $n_{\mathrm{DS}}=16, z$ $=-0.72(16)=-11$. This is the effective charge of DS for $r_{\mathrm{s}}$ $=15 \AA$. A similar calculation for DS with $r_{\mathrm{s}}=18 \AA$ A, the size used in the recent study by Mayer et al. (33) with rats, yields $z$ $=-17$.

Previous estimates of $z$ for DS were based on measurements of electrophoretic mobility (16). The relationship derived yields a much smaller value for $z,-3.7$ at $r_{\mathrm{s}}=15 \AA$ vs. the present value of -11 . The problem with the electrophoretic mobility approach is that there is a complex and not fully characterized relationship between the charge distribution on a linear polyelectrolyte, its hydrodynamic behavior, and its electrophoretic mobility. It is likely that the model used to interpret the mobility measurements was oversimplified. Recent data on the diffusion of polystyrene sulfonate through charged membranes (40) supports the use of a stoichiometric charge corrected for counterion condensation.

\section{Acknowledgments}

We wish to thank Gunta Grislis, Suzanna Ernst, and Joan Bialek for their expert help in characterizing the physicochemical properties of dextran sulfate. We also express our gratitude to Ueno Fine Chemicals, Osaka, Japan for providing us with the FDA-approved dextran sulfate preparation used in this study.

This study was supported by the following grants from the National Institutes of Health: DK29985-05, DK40800-04, and DK20368-13 from the National Institute of Diabetes, Digestive and Kidney Diseases, and the General Clinical Research Center Resources Grant RR00070 .

\section{References}

1. Chang, R. L. S., I. F. Ueki, J. L. Troy, W. M. Deen, C. R. Robertson, and B. M. Brenner. 1975. Permselectivity of the glomerular capillary wall to macromolecules. II. Experimental studies in rats using neutral dextran. Biophys. J. 15:887-906.

2. Oken, D. E., B. B. Kirschbaum, and D. M. Landwehr. 1981. Micropuncture studies of the mechanisms of normal and pathologic albuminuria. Contrib. Nephrol. 24:1-7.

3. Baldamus, C. A., R. Galaske, G. M. Eisenbach, H. P. Krause, and H. Stolte. 1975. Glomerular protein filtration in normal and nephritic rats. Contrib. Nephrol. 1:37-49.

4. Chang, R. L. S., Robertson, C. R., W. M. Deen, and B. M. Brenner. 1975. Permselectivity of the glomerular capillary wall to macromolecules. I. Theoretical considerations. Biophys. J. 15:861-886.

5. Bennett, C. M., R. J. Glassock, R. L. S. Chang, W. M. Deen, C. R. Robertson, and B. M. Brenner. 1976. Permselectivity of the glomerular capillary wall: studies of experimental glomerulonephritis in the rat using dextran sulfate. $J$. Clin. Invest. 57:1287-1294.

6. Bohrer, M. P., W. M. Deen, C. R. Robertson, J. L. Troy, and B. M. Brenner. 1979. Influences of molecular configuration on the passage of macromolecules across the glomerular capillary wall. J. Gen. Physiol. 74:583-593.

7. Chagnac, A., B. A. Kiberd, M. C. Farinas, S. Strober, R. K. Sibley, R. Hoppe, and B. D. Myers. 1989. Outcome of the acute glomerular injury in proliferative lupus nephritis. J. Clin. Invest. 84:922-930.

8. Shemesh, O., J. C. Ross, W. M. Deen, G. W. Grant, and B. D. Myers. 1986. Nature of the glomerular capillary injury in human membranous glomerulopathy. J. Clin. Invest. 77:868-877.

9. Guasch, A., H. Hashimoto, R. K. Sibley, W. M. Deen, and B. D. Myers. 1991. Glomerular dysfunction in nephrotic humans with minimal changes or focal glomerulosclerosis. Am. J. Physiol. (Renal Fluid Electrolyte Physiol.) 29:F728-F737. 
10. Myers, B. D. 1990. Pathophysiology of proteinuria in diabetic glomerular disease. J. Hypertens. 8:S41-S46.

11. Scandling, J. D., V. M. Black, W. M., Deen, and B. D. Myers. 1992. Glomerular permselectivity in healthy and nephrotic humans: Necker's Seminar in Nephrology. Adv. Nephrol. 21:159-176.

12. Thomas, D. M., A. N. Hillis, G. A. Coles, M. Davies, and J. D. Williams. 1991. Enalapril can treat the proteinuria of membranous glomerulonephritis without detriment to systemic or renal hemodynamics. Am. J. Kidney Dis. 18:38-43.

13. Ala-Houhali, I., and A. Pasternack. 1987. Fractional dextran and protein clearances in glomerulonephritis and in diabetic nephropathy. Clin. Sci. 72:289296.

14. Remuzzi, A., E. Pertucucci, P. Ruggenenti, L. Mosconi, M. Limonta, and G. Remuzzi. 1991. Angiotensin converting enzyme inhibition improves glomerular size-selectivity in IgA nephropathy. Kidney Int. 39:1267-1273.

15. Deen, W. M., C. R. Bridges, B. M. Brenner, and B. D. Myers. 1985. Heteroporous model of glomerular size-selectivity: application to normal and nephrotic humans. Am. J. Physiol. (Renal Fluid Electrolyte. Physiol. 18) 249:F374-F389.

16. Deen, W. M., B. Satvat and J. M. Jamieson. 1980. Theoretical model for glomerular filtration of charged solutes. Am. J. Physiol. 238 (Renal Fluid Electrolyte Physiol. 10):F126-F139.

17. Bohrer, M. P., C. Baylis, C. R. Robertson, and B. M. Brenner. 1977. Mechanisms of the puromycine-induced defects in the transglomerular passage of water and macromolecules. J. Clin. Invest. 60:152-161.

18. Battilana, C., H. Zhang, R. Olshen, L. Wexler, and B. D. Myers. 1991. PAH extraction and the estimation of plasma flow in the diseased human kidney. Am. J. Physiol. 30 (Renal Fluid Electrolyte Physiol.):F726-F733.

19. Flexner, C., P. A. Barditch-Crovo, D. M. Kornhauser, H. Farzadegan, L. J. Nerhood, R. E. Chaisson, K. M. Bell, K. J. Lorentsen, C. W. Hendrix, B. G. Petty, et al. 1991. Pharmacokinetics, toxicity, and activity of intravenous dextran sulfate in human immunodeficiency virus infection. Antimicrob. Agents Chemother. 35:2544-2550.

20. Knisel, W., M. Muller, I. Besenthal, A. di Nicuolo, M. Rebstock, T. Risler, and M. Eggstein. 1991. Application of a new LDL apheresis system using two dextran sulfate cellulose columns in combination with an automatic column-regenerating unit and a blood cell separator. J. Clin. Apheresis. 6:11-15.

21. Bohrer, M. P., W. M. Deen, C. R. Robertson and B. M. Brenner. 1977. Mechanism of angiotensin II-induced proteinuria in the rat. Am. J. Physiol. 233(Renal Fluid Electrolyte Physiol. 2):F13-F21.

22. Boyce, N. W., and S. R. Holdsworth. 1985. Glomerular permselectivity in the isolated perfused rat kidney. Am. J. Physiol. 249 (Renal Fluid Electrolyte Physiol. 18):F780-F784.

23. Chang, R. L. S., W. M. Deen, C. R. Robertson and B. M. Brenner. 1975 Permselectivity of the glomerular capillary wall. III. Restricted transport of polyanions. Kidney Int. 8:212-218.
24. Olson, J. L., T. H. Hostetter, H. G. Rennke, B. M. Brenner and M. A. Venkatachalam. 1982. Altered glomerular permselectivity and progressive sclerosis following extreme ablation of renal mass. Kidney Int. 22:112-126.

25. Olson, J. L., H. G. Rennke and M. A. Venkatachalam. 1981. Alterations in the charge and size selectivity barrier of the glomerular filter in aminonucleoside nephrosis in rats. Lab. Invest. 44:271-279.

26. Rennke, H. G., Y. Patel, and M. A. Venkatachalam. 1978. Glomerular filtration of proteins: clearance of anionic, neutral, and cationic horseradish peroxidase in the rat. Kidney Int. 13:324-328.

27. Vanrenterghem, Y., R. Vanholder, M. Lammensverslijpe, and P. P. Lambert. 1980. Sieving studies in urea-induced nephropathy in the dog. Clin. Sci. 58:65-75.

28. Weening, J. J., and H. G. Rennke. 1983. Glomerular permeability and polyanion in Adriamycin nephrosis in the rat. Kidney Int. 24:152-159.

29. Weening, J. J., and A. Ven der Wal. 1987. Effect of decreased perfusion pressure on glomerular permeability in the rat. Lab. Invest. 47:144-149.

30. Whiteside, C., and M. Silverman. 1984. Glomerular and postglomerular permselectivity to anionic dextrans in the dog. Am. J. Physiol. 247 (Renal Fluid Electrolyte Physiol. 14):F485-F495.

31. Bohrer, M. P., C. Baylis, H. D. Humes, R. J. Glassock, C. R. Robertson, and B. M. Brenner. 1978. Permselectivity of the glomerular capillary wall: facilitated filtration of circulating polycations. J. Clin. Invest. 61:72-78.

32. Mogensen, C. E., and K. Solling. 1977. Studies on renal tubular protein reabsorption: partial and near complete inhibition by certain amino acids. Scand. J. Clin. Lab. Invest. 37:477-486.

33. Mayer, G., R. A. Lafayette, J. Oliver, W. M. Deen, B. D. Myers, and T. W. Meyer. 1993. Effects of angiotensin II receptor blockade on remnant glomerular permselectivity. Kidney Int. 43:346-353.

34. Bertolatus, J. A., and L. G. Hunsicker. 1985. Glomerular sieving of anionic and neutral bovine albumins in proteinuric rats. Kidney Int. 28:467-476.

35. Maddox, D. A., W. M. Deen, and B. M. Brenner. 1992. Glomerular filtration. In Handbook of Physiology. Section 8: Renal Physiology, Volume 1. E. E. Windhager, editor. Oxford University Press, New York. 545-638.

36. Oliver, J. D. III, S. Anderson, J. L. Troy, B. M. Brenner, and W. M. Deen. 1992. Determination of glomerular size-selectivity in the normal rat with Ficoll. J. Am. Soc. Nephrol. 3:214-228.

37. Bohrer, M. P., G. D. Patterson, and P. J. Carroll. 1984. Hindered diffusion of dextran and ficoll in microporous membranes. Macromolecules. 17:11701173.

38. Davidson, M. G., and W. M. Deen. 1988. Hindered diffusion of water-soluble macromolecules in membranes. Macromolecules. 21:3474-3481.

39. Manning, G. S. 1969. Limiting laws and counterion condensation in polyelectrolyte solutions. I. Colligative properties. J. Chem. Phys. 51:924-933.

40. Lin, N. P., and W. M. Deen. 1992. Charge effects on the diffusion of polystyrene sulfonate through porous membranes. J. Colloid Interface Sci. $153: 483-492$ 